\title{
MIENTRAS CAMINA
}

José Abraham Guevara Chamorro

(C) UNAN-Managua

Recibido: mayo 2017

Aprobado: junio 2017

(c) (i) (2)

Mientras camina, hunde los brazos en el aire. Nada lo detiene, atropella a quien le sale a su paso. Dijo que es de Rivas. - ¡Je, je! La ciudad de los mangos, ije, je! Prosigue su recorrido; reparte golpes con sus brazos al azar. Va en el pasillo de punta a punta, una distancia de diez metros. Lo ha estado haciendo desde las seis de la mañana, ahora que son las doce meridiano, seguirá, pero enfilado, anunciaron la hora de almorzar. Manuel, alto, de tez azulada, brilla con el sudor a cuesta, sus extremidades largas le ahorran distancias. Julio Villachica abandona la plazoleta del patio central. El periplo de las regaderas al patio, es su deleite apenas se levanta. Largo tiempo pasa expuesto a los rayos del sol, su cuerpo parece el de un marinero, con su dorada piel. Julio, a él nadie acá le conoce la voz, y no es que sea sordomudo, porque oye, más cuando anuncian la hora de las comidas. El tiburón, así le dicen, un descuido de un comensal, y Julio lo deja sin su alimento.

Manuel va en la fila detrás de Sabatini, a quien el dragón añil le resguarda la espalda, por el frente sus zarcos ojos a lo Rasputín, son dantescos. ¡Qué locura todo esto! Son cincuenta y cuatro individuos, diversos caracteres, distintas circunstancias se han congregado en este lugar.

\section{3}

—Los únicos que dialogamos, somos nosotros dos, verdad Vinicio.

-Así es, Oscar.

-Ojala que la Licenciada no se aparezca con esa comida extraña. ¿Cómo dijo que se Ilama, Vinicio?

- ¡Pavo horneado!

-Es insípido, y no tenemos más alternativa que comerlo, la licenciada Carmen, siempre espera hasta que la terminemos.

- Yo voy hacer el simulacro, Oscar, de comerlo, fingiré, ya que en el menor descuido de ella, arrojaré la boñiga de comida al monte.

-Vos Vinicio, no has leído ninguna página del Libro. Me quedé anclado en la parte que dice: - no es lo mismo llegar al rotulo que dice; aquí es Bombay, devolverse, y decir he llegado a Bombay\|l. 
-Poco o nada me interesa de ese libro, u otro. No sé cómo te encanta a vos Oscar, leer y leer, por eso creo que siempre te vas al fondo, donde empiezas a dramatizar lo que lees.

—Ya, ya, Vinicio, mejor fumémonos un cigarrito, mejor si son de los tuyos.

- Solo te recuerdo, Oscar, que después es tu turno, no quiero discutir contigo de a quien le toca.

Sonó el fosforo y de inmediato con la llama fulgurante, encendieron los cigarros. El dialogo cesó, intercambiaron expresiones, a través de los ojos. Las sonrisas de ambos, denotaba lo complacido que estaban. Eran los únicos dos que podían fumar como en una eternidad, en aquel poblado lugar.

Él siempre se distinguía por su soledad, no reparaba en ninguno de sus vecinos. A veces lo atropellaban y ni así se inmutaba. Nadie lo vio perder el control por muy asediado que fuera. Polín le decían, vino de Boaco. Poseía una cara bonachona. Sus ojos pequeños como de cusuco, escondían su verdadera personalidad, o mejor dicho no revelaban nada de él. Se bañaba, andaba por el sitio, comía y se dormía por la noche. No se le vio dormir de día, nunca.

Por la noche el cajón de aquel edificio verde, gemía. Ambulantes sábanas blancas manchaban la oscuridad. Los ruidos que hacían las ratas, eran diáfanos en el silencio de la lobreguez. La procesión de almas albas se traspasaba uniéndose solo en el instante de su leve fusión, para luego resurgir. Infinito se pavoneaba el misterio de lamentos, surgidos desde los huecos de las tuberías. Debía estar alerta.

Ante el menor incidente, listo.

El primer cadáver localizado entre unos arbustos del patio trasero del comedor, de inmediato fue diagnosticado como muerte natural. Perteneció a un hombre pequeño, encorvado, de unos cuarenta años. Acostumbrado a recoger chivas de cigarro apagadas, e introducirlas en su boca, las empujaba con su lengua al cielo de su cavidad. Caminaba con las manos enlazadas por la espalda, la vista en picada, su calvicie brillaba por el corredor externo de la casona verde.

Aquella muerte pronto dejo de ser acontecimiento. En la casona verde la vida continúo con su rutina, hasta que otro hombre fue encontrado por los custodias, tendido sobre la banca de concreto del patio delantero de la sección de Mujeres, Tieso. La alarma se elevó. ¡Sorpresa! El hombre difunto, era el infortunado Julio Vichachica. Aquí hubo estupor. Julio, según los últimos exámenes rutinarios, de hace cinco días atrás, arrojaron una salud envidiable. El ambiente de la casona verde se tornó agitado, los nervios se encimaron en todos. Las reuniones de

autoridades de la casona se dieron continuas. La vigilancia se incrementó y los ojos escudriñadores más avispados. 
No se había enfriado el cadáver del Tiburón, cuando a los dos días otro cadáver. Éste tenía los ojos brotados, lacerada la espalda, sus largas extremidades estaban violáceas. El cadáver pálido, con la boca abierta pareció a la hora de su final revelarnos algo. El conteo de la casona verde, declaro en la ausencia, que se trataba de Mateo Sabatini, originario de la ciudad de Sebaco. Las cuencas oscuras de Sabatini anularon su ferocidad.

El aislado sitio de la casona, pronto fue invadido. Inspectores de la estación dos de policía de Managua, empezaron a interrogar al personal de custodia de la casa verde. A unos los indagaron en el lugar, otros fueron citados a la delegación policial.

Las investigaciones se prologaron ante la falta de certeza en las conclusiones del peritaje policial. El asunto se durmió, hasta que fue levantado de nuevo por dos muertes más. El hombre de Rivas ya no volvería a sentirse orgulloso de su ciudad, la de los mangos, ni a dar sus interminables caminatas dentro del pasillo de la casona. Ahorro de golpes, que feliz se hubiera sentido el Tiburón de una boca menos. Manuel cual largo era, yacía con su cara, sobre la enorme lengua, que salía

37

del cadáver de Sergio Domínguez. La cantidad de fallecidos llegó a cinco. La casona verde ardió en locuras. Los fiscales invadieron el lugar, auxilio judicial de la policía se hizo cargo de las muertes, aun no esclarecidas.

Estos acontecimientos fueron seguidos con atención minuciosa por Vinicio y Oscar, los únicos ciudadanos de la casona verde, que al menos podían mantener una conversación coherente.

— ¡Qué barbaridad, Oscar, el pobre Julito, hasta Mateo!

-Y, Sergio, ya no dispara sus golpes de boxeador, descanso a sus muñones, ya no habrá porque metérselos a su boca sin dientes.

—Pienso que pudo haber sido el Príncipe, el responsable de las muertes, no piensas así, Oscar.

— ¡Uh! No lo creo, más bien parece obra de Manzano, para no estarse molestando en arriar los enfermos. Con menos, descansa más.

—No lo sé, Oscar, cualquiera de estos individuos, son capaces de estrangular un chancho.

— ¡Un momento, Vinicio! Ve allá, por el pasillo de afuera, ahí llevan a Alfredo, también va Polín, si éste ni se mete con nadie. Acaso sospecharan de los dos. De Alfredo quizá, pero de Polín no lo creo. Tal vez es que nos llamaran a todos, incluyendo a nosotros dos. Son rutinas de investigación, a las cuales no debemos tener miedo, Vinicio, verdad. 
-Yo, estoy tranquilo, no le he puesto mis manos a ninguna garganta por este lugar. A mí que me investiguen lo que quieran los policías, total no les he tenido miedo, ya he tratado con ellos anteriormente.

-El momento que les tuve miedo, fue cuando me garrotearon dentro de la Iglesia de San Marcos. En aquella ocasión sentí la muerte bajo la lluvia de bastones que me dejaron ir. Con solo verlos se me enchina la piel. Deseara que nunca me llamaran, tócame, Vinicio.

-Estate tranquilo. Vas a ver, la licenciada Carmen, abogaría por nosotros, ante cualquier injusta acusación que nos hicieran. No te desesperes, Oscar.

La trabajadora social, Zullen, casi cae al piso encerado, al doblar hacia la oficina que servía de interrogatorio, gracias a la psicóloga Sonia que le agarro del brazo no

39

cayo. Ambas se unieron a las pesquisas. Cifraban las cuatro de la tarde, cuando salió de la oficina Alfredo.

La tarde moría en el silencio, y antes que falleciera para dar vida a la noche, un grito tenebroso como un disparo, se atravesó por las paredes de la oficina, invadiendo a toda la casona verde.

— ¡Ya déjenme en paz!

- ¡Basta, no molesten más!

- ¡Carajo, suéltenme las manos!

Los gritos del hombre, eran desgarradores. Se escuchaba el enorme desconcierto en aquel recinto. Las sillas hundidas contra el piso una y otra vez, evidenciaba la lid del hombre pidiendo libertad.

— ¡Hay, hay! Suéltenme, se los ruego.

- ¡Mamá!

- ¡Basta, basta!

Luego de ese basta, el silencio retornó, pareció que un sueño dominara a todos, pasaron uno dos minutos, las voces ya como en susurros apenas se percibieron afuera. La calma zozobró, emergiendo nuevamente el energúmeno a vociferar:

- ¡Sí, sí, ya no jodan!

- ¡Fui yo! 
-Estoy molesto, bien enojado con ustedes. No me dejaron terminar mi meta. Eran seis los que tenía planificado estrangular. Sólo me dejaron hacerlo con cinco.

-A Mateo le saque los ojos, porque me daban terror su color. Se hizo fácil, le hundí el tenedor en cada ojo, de un solo tirón se los destripe. Se miraba mejor sin ellos.

—Julio, él me las debía, muchas veces me arrebató mi comida. Por poco se me escapa, pero pudo más mi fuerza que la de él. Pase bastantes minutos con mis manos apretada sobre su garganta por miedo a que respirara todavía.

— ¡Ja, ja! Jamás me volverá a golpear, Sergio, ni Manuel.

Un silencio melancólico compareció, enmudeciendo a todos. Los oficiales de la Dirección de auxilio judicial, fueron los primeros en marcharse, seguidos de los fiscales, no así el personal administrativo de la casona verde. Una larga noche les esperaba en la oficina. Las afanadoras de turno se multiplicaron llevando café y repostería para la jornada nocturna.

-Polín, Polín, quien se lo iba a imaginar, Vinicio.

-Estoy anonadado, Oscar, no lo puede creer todavía, Polín, el dulce Polín. Sí con nadie se metía.

- Cuantos caballos de fuerza ocultaba Polín. Siendo un hombre pequeño, no pareciera que tan descomunal energía surgiera de él. Si hasta un animal inofensivo se mira con sus ojitos de cusuco. Vinicio, de hoy en adelante, andaré arisco. Donde menos uno espera surge la sorpresa. ¡Cuídate, Vinicio!

-Nos cuidaremos, Oscar, ambos nos defenderemos de estos esquizofrénicos. Por muy chiquitos que sean.

Se apagaron las luces, dando paso al rato, al viaje de las sábanas alboradas; los gemidos en la tubería. Las chinelas caminaron esa noche. 